\title{
The Importance of William James" Theory of "Fringes" to the Constitution of a Phenomenology of Perception
}

\author{
Carlos Morujão \\ Universidade Católica Portuguesa \\ cmorujao@fch.lisboa.ucp.pt
}

\begin{abstract}
This paper focus on the phenomenological theories of perception and intuitive acts in general, and aims to show the relevance of William James' concept of fringe to understand them. Although Husserl claims that James' analysis were carried on without the phenomenological reduction and were thus biased by psychological and physiological prejudices, the paper stresses the high value of those analysis: James' intended to remain faithful to the meaning of lived experience and avoided any considerations where descriptions could be entangled with uncriticized philosophical theories (e.g. about the nature of brain states). The paper also aims to show that James' importance for Husserl could be extended beyond the explanation of acts intending singular individuals to the acts intending universal objectivities and essences.
\end{abstract}

Keywords: Phenomenology of Perception, Noetic-Noematic Correlation, Facts and Essences, Fringes

\section{Introduction}

The perception of an individual object and the process of picking up its individual characteristics are, in Husserl's technical language in the Logical Investigations, "founding acts". But their basic nature must not hide the complexity of the cognitive activity already at work; in order to achieve the constitution of the unity of the perceived object, consciousness must engage in a process of synthesis of the continuum of partial intentions directed to each temporal phase of its appearance. The fact that this process has a clear 
teleological character doesn't mean that, for Husserl, the existence of a real transcendent object is only a probability that would remain a long time waiting for a confirmation. The certainty of the existence of the object follows directly from the first perceptive contact with it; of course, any belief can be subjected to processes of modalization (the certain can later become hypothetical or even doubtful), but the evidence of an existence is never the conclusion of a reasoning that begins with a mere probability.

The ties that link intentional consciousness to the appearance of an individual object are different and much stronger than those that link it (in acts "founded" in the ones mentioned above) to abstract or ideal objectivities. The first appearance of an individual opens certain horizons that will determine the future relation to it and consciousness' recurrent movement from new sensegiving acts (directed to that same individual) to their awaited fulfilment. Even the phantasy of an individual thing belonging to an imaginative world, or the remembrance of a past perception of an individual thing in the real world, imposes upon us certain lines along which imagination and remembrance must go on, if the coherence of the imagined or remembered worlds is to be preserved. Noeses of imagining or remembering are only modifications of perceptions and not modifications of the fundamental laws governing the presentation of an object, laws that still hold when it is just re-presented. And perhaps they still hold for the recognition of personal identity. There are laws for the overlapping of states of mind (however distant in time) that account for the identity of a singular stream of consciousness and which prevent the state of mind of an individual $X$ to be mixed with any state of mind of another individual Y. To address all these issues, James created the concept of «fringe». I intend to show its influence on Husserl's thought, focusing in the problem of perception.

\section{A noetic approach to perception}

If we take a noetic approach to the problem of perception we note that two different things happen: 1) every actual presentation of an object is surrounded by a halo of vague indications of possible new presentations (Husserl, 1966: 5);

2) in any presentation two different levels of sense-giving acts may be 
distinguished, to which correspond, from the noematic side, two kinds of objectivities. Consequently, we speak of a first level of meaning - the one I mentioned in the first paragraph - that corresponds to the experience of an object as an existence whose phases of appearance are temporally connected in the unity of the same stream of consciousness. Husserl seems to say that unity is a weak form of identity: when I see the different temporal phases (sc. phases A and B) of the appearance of an object X, I just know that it is the same object appearing without the help of an explicit act of identification.

The second or higher order level of meaning - engendering complex noematic relations such as comparisons, collections or essences -, which as I said before is "founded" in the first, arises in four different ways: 1) in so far as the appearance of an object is seen as similar to other individual appearances; in this new kind of act I explicitly acknowledge that $\mathrm{A}=\mathrm{B}$ and consequently (A and $\mathrm{B})=\mathrm{X}$, i.e. the appearing object. 2) in so far as the object can be seen as an instantiation of a species; 3 ) in so far as one of his moments (e.g. its color) can also be seen as an instantiation of a species or of a set of articulated species; 4) in so far as it has formal relations with other objects ${ }^{1}$. All this happens because when consciousness enters in a first level intentional relation, like the encountering of a sound or a color, it cannot avoid entering in new levels of objectivation, thus engendering new forms of objective unity (Husserl, 1984c: 290). Perhaps my former example $(A+B)=X$ has to be developed in order to get a full understanding of these characteristics of normal lived experiences. Probably what happens is more like this:

$$
(\mathrm{An}+\mathrm{Bn}+\ldots+\mathrm{Zn} \ldots)=\mathrm{X}
$$

A moment " $n$ " - for instance, the red color - was picked up in the temporal phases of the apprehension of $\mathrm{X}$. If I call $(\mathrm{A}+\mathrm{B}+\ldots+\mathrm{Z})=\mathrm{X}-$ following the terminology of William James (James, 1909: 216) - the theme of an intentional act, "n" will be something that always goes along with it and to which I may

\footnotetext{
${ }^{1}$ Formal relations are perhaps the most difficult issue to deal with and I also don't address it at full length in my paper. Formal relations must obtain between very different kinds of objects. We must be able to vary them almost indefinitely even to a point where there is no more the possibility of an intuitive fulfillment. In this last case we face what Husserl sometimes calls «empty essences»; cf. Husserl (2012: 43).
} 
direct my attention if I abstract " $n$ " from whatever I also encounter in $X$ in the temporal phases A, B ... Z of my experience of it. Above all, I want to stress the fact that this process is only understandable because all temporal phases of the appearance of individual objects point beyond themselves. Perception is not only the recurrent movement I mentioned above from sense-giving acts to fulfilment; another important movement goes from vague ${ }^{2}$ intentions, in one phase (like intending " $n$ " in phase A), to explicit expectations in future phases (intending " $n$ " in phase B) (Husserl, 1966: 12-13). However, objects like X, although they are completely independent individuals and their individuality rests, so to speak, on their own being, point beyond themselves too. To explain why all this happens, I will look for help in William James's theory of the fringes and in his distinction between substantive and transitive states.

Aron Gurwitch has also addressed the relation between James' theory of the fringes and Husserl's theory of perception (Gurwitch, 1957: 246). Nevertheless, his main interest was to show that what he called the "marginal consciousness" - i.e. the consciousness of whatever surrounds the topic of an intentional act - is always more or less structured, operating selections according to criteria of relevance for the content it focus. James was above all worried with the distinction between knowledge and mere representation. If in the process $(\mathrm{A}+\mathrm{B}+\mathrm{C})=\mathrm{X}$ I only pick-up a sensation that affects me in one of the temporal phases of my experience of $\mathrm{X}$, he argued that I will only have a representation of $X$ in this precisely moment; on the other hand, if I pick-up the entire process $(\mathrm{A}+\mathrm{B}+\mathrm{C})$ and an harmonious psychic connection between the temporal phases of my experience follows, then I will have knowledge of $\mathrm{X}$. I follow a trend of thought slightly different from Gurwitch's, although not entirely opposed to it. I address the problem of selections in the next section of my paper.

\section{Selections in the stream of consciousness}

At the beginning of Chapter XI of his Textbook of Psychology William James says that no immediate experience of ourselves gives us pure sensations as

2 "Vague" is my translation of the German "Leere". 
elementary psychical processes, nor even complex states of mind that could be regarded as a composition of sensations. Psychology Handbooks, according to James, fail to differentiate most of the times physiological from psychological states. What corresponds to our immediate experience of ourselves is a permanent process of coming and going of states of mind, succeeding each other in time (James, 1909: 196). To characterize this process James coined the well-known expression "stream of consciousness". But this stream is also a process of spontaneous selection: we may be interested in some of its parts, while other parts disappear from lively awareness ${ }^{3}$. What's really noteworthy in all this is the fact that sometimes a person makes the same more or less spontaneous selection he has made before and arrives at the same results; for instance, the selection of the same section of the space-time continuum and the reckoning that it is filled with the same object. In other cases, may occur the selection of two different sections, followed by the acknowledgment they are filled with similar objects. Other cases may also occur: two or more different selections that were thought to be filled in the same way are in a later phase of the process reckoned as being differently filled. This process doesn't go on indefinitely and I will come later to its specific legality.

Also noteworthy is the fact that other people, who have different streams of consciousness and usually make different selections from our owns, may sometimes make exactly the same selections - as if they had the same purposes as we - and arrive at results that overlap our own results or overtly coincide with them. For instance, if two different people keep watching the fly of the same bird, they have made the same relevant selection in their different streams of consciousness and may utter two very similar assertions about what they see $^{4}$. They would agree there is a bird flying, and perhaps agree about its

\footnotetext{
${ }^{3}$ Perhaps we could say that we are not attentive to them, but with three conditions: 1) attention is grounded in the intentionality of consciousness and not the other way round; 2) the focus of attention can be changed, and what was initially a part of the horizon surrounding the intended object can become the focus of attention; 3 ) the intensity of attention is not directly dependent on the intensity of a physical stimulus and attention can be directed either to real mundane objects or to ideal and categorical objects. I will come back to this later.

${ }^{4}$ Of course they may not make any assertion, but then it would be doubtful for an observer that they have made the same relevant selection. Perhaps the observer could
} 
species, but they could also debate, in case of further disagreement, about the species of the bird they are watching, on the common basis that it's really a bird. As in the former case, in normal situations this process doesn't go on indefinitely.

Even if the disagreement I have just mentioned is improbable in these trivial circumstances, and even if it were very unlikely to happen in most of the cases, we can never rule out the possibility of its occurrence. And this permanent possibility has to do with something pertaining to the essence of every perceptive act. Two different persons don't have the same perspective about the things they are perceiving. Instead, they always have different perspectives dependent on their spatial (and sometimes also temporal) locations -, and it is always on this basis that they may try to reach a common agreement about what they see. In a more technical language we could only say that although the respective perceptual noemata are never exactly the same, in most of the everyday life-world experience of human beings they are so alike (to the point of having the same content) that they are directed to the same reference and the possibility of an actual disagreement is very small. Nevertheless, the possibility of a total coincidence of the perceptual noemata is excluded by the essence of perception.

Phenomenology aims to give an account of experiences like the ones mentioned, but the phenomenological way of doing it is rather complex. These experiences have an empirical content and they could easily be described by psychology; but they also have an a priori condition, laying in the nature of the subject and in the nature of the object perceived. Perhaps we can introduce the phenomenological way of addressing this issue with a comparison. Someone who is looking to the peel of an unpeeled orange cannot see, at the same time, the inside of that orange; to be able to do this he or she must accomplish another intentional act, from a different point of view. Nevertheless, the peel is the peel of a certain inside and doesn't exist as a peel without a permanent relation to it. No one would say that the inside doesn't exist until the moment he or she can see it, because that's the opposite that it's true: the inside of an orange is that invisible part of it that lies under the peel and can only be seen after peeling the orange

say that they have after watching their respective head movements, but it would hardly be more than a guess. That's a very complicated issue. 
(Husserl, 1984b: 589). Two different empirical situations, i.e. two different ways of looking at the same orange are linked by a non-empirical legality connecting the visible with the hidden.

Now, this connection is not arbitrarily made by perceptive consciousness. The stream of consciousness cannot flow at random: it's a process with its own legality, which can be grasped if we just describe what happens in a perceptive act without presuppositions. I can't imagine an orange (a real orange, I mean, not a fake) with a peel and no inside, because it wouldn't be the material orange of a real or possible life-world experience. The non-fulfilment of the expectation of finding an inside under the peel would force me to acknowledge a previous error, when I thought it was a real orange I was perceiving. Now, that this connection I am talking about is not just presupposed, but can be actually seen - i.e. it is the correlate of an intentional act -, is I think a shared phenomenological assumption. And so I may proceed with my analysis, aiming to uncover, under our immediate perceptive experience, a deeper level of essences, categories and horizons (Husserl, 1968: 64). Just to finish this section of my paper let me add that the kind of connection I am talking about doesn't entail that the phases of the stream that we connected have to follow each other closely in time; two separated phases may be connected as long as a coherent structural relation subsists between them (Husserl, 1950a: 89). How much time can elapse between two phases in order to the connection still be possible is, of course, an empirical question; perhaps it varies from person to person.

\section{Facts and essences}

Perceptions can be repeated, can be remembered, or can be imagined. The object perceived in an actual experience is likely to change, in this process, its initial status. From a mere individual it can become an instantiation and its appearances overlap. That's a process Husserl called "synthesis of homogeneity" (Husserl, 1966: 128). Looking at an orange or at several oranges we can go on making different kinds of selections in the perceptual field and next compare the results. For instance, we know that an orange remains the same orange before and after being peeled; that a bitter orange is still an orange just like the sweet one we have just tasted; that slight differences in color or in 
shape between two oranges are irrelevant to their identification as oranges. And we could go on, sometimes just imagining we are perceiving an orange appearing in our visual field in such and such a way. Before looking to what Husserl has to say about this in Ideas I let's see one of the clearest explanations of this process he offered us:

«[...] we can see and with absolute certainty that exercising an arbitrary variation, and as long as what differs in the variation is indifferent to us, a so to speak permanent coincidence of the variants is maintained, and, as a quid or a content of what is necessarily and invariably maintained in the coincidence, a general essence.» (Husserl, 1968: 83)

In the first section of the first volume of Ideas Husserl addresses the problem of the relation between a singular individual and its essence. The singular individual can enter in a set of endless relations with other singular individuals, according to the essence of each of them. At the same time, each individual is the particular instantiation of a set of essences that relate to each other according to the traditional notions of genus and species, or, as Husserl also says, of totality and part (Husserl, 1950c: 31-32).

The first section of Ideas I gives us another important distinction. In $\S 6$ Husserl distinguishes between an eidetic universality and a legal, i.e. empirical universality (Husserl, 1950c: 20). This new distinction is not so easy to grasp as the ones we made before. It seems that the same singular individual can be at the same time an example of an eidetic and of an empirical universality, and that he is an example of the first or of the second depending on the fact that his existence is or is not posited. I think Husserl's examples of this difference are rather confusing, but prima facie he is saying something like this: if we take a natural phenomenon and explain it according to a geometrical truth (we may think of the elliptical orbit of the planets around the sun), we are speaking about empirical universalities; elliptical orbits are a consequence of some real natural phenomena happening in our physical universe. As a consequence, if we knew the present state of a natural object, the totality of the laws of nature and the present state of the rest of the world, we would be able to fully determine the essence of the object in question (Husserl, 2012: 84). On the other hand, it seems that an individual phenomenon is an example of an eidetic universality 
if its relation to its essence would subsist even if it were thought as a nonexistent entity. Husserl's example is the same example Kant choose to give an example of analytic judgements: all material bodies are extended in space. In spite of speaking about material bodies, we are not saying now that they exist - in other words, their existence is not "posited" -, but only that a certain relation subsists between their possible existence and the spatial extension. I think that what Husserl wants to say is that in every being we can perceive the same essential features of all other beings of his region of Being. But I don't think that Husserl ever meant that any singular individual can appear as an example both of an eidetic and an empirical universality. If I have, for instance, a pair of Italian shoes I may say they instantiate the empirical universal "Italian shoes", but it's difficult to imagine what could be the meaning of such a universal if de facto there were not and had never been Italian shoes in our empirical world.

\section{Formal relations}

This brings us back to the Logical Investigations. In this work Husserl had spoken of analytical necessities. That's what happens in sentences entirely built with formal concepts; for instance: if $\mathrm{a}>\mathrm{b}$ and $\mathrm{b}>\mathrm{c}$, then $\mathrm{a}>\mathrm{c}$. These analytical necessities may face particularizations, as it happens when we admit the existence of material or physical bodies: if the Eiffel tower is higher than the London tower and the London tower is higher than the Pisa tower, then the Eiffel tower is higher than the Pisa tower. But in this case the necessity would then refer to an empirical particularization of an analytical - or essential - law, and again would not mean the empirical "position" of an existence (Husserl, 1984a: 259). (We can know from experience that these three monuments exist in the real world, but that's irrelevant for our present issue.) This trivial example - it can probably fall under the category of what Husserl used to call klein Geld, in which he saw the early stages of any rigorous phenomenological analysis shows us three important things: 1) the relations between the Eiffel tower, the London tower and the Pisa tower can be entirely formalized, at least regarding some levels or strata of our experience of them (it would be absurd to formalize their respective architectonic value); 2) this formal structure determines the way 
they appear to us and is inseparable of our experience of them; it means that I cannot change it at my will 5 ;) the relation we acknowledged between the Eiffel tower, the London tower and the Pisa tower obtains even if someone only knows, say, the Eiffel tower and is totally ignorant of the existence of the other two: and it also obtains between the Eiffel tower and any other two objects whose high is in a similar relation with it. Perhaps we can also add that a similar formal relation would subsist between any fictitious entities we are able to imagine, as long as we maintain their respective identities.

We have so far mentioned two different albeit related processes. In the first place, the process in which we take the successive or simultaneous appearance of similar objects as meaning the appearance of the same kind (the same genus or species) of objects; and, in the second place, the process of variation of a set of objects that have between them the same kind of formal relations. In both cases, we took as our point of departure a series of individuals, but not as a factical series (Husserl, 1999: 413). In both cases we have dealt with a series that was arbitrarily chosen, in the sense that the individuals could have been different as long as their general characteristics would remain or their formal relations would be the same. It seems that there is only one criterion we have to respect: the consciousness that we can proceed arbitrarily in the same way as we did before. Husserl calls this kind of consciousness "wonderful" (merkwürdige) and "important" (wichtige):

To each multiplicity of variation belongs essentially this wonderful and so particularly important consciousness of the "and so on at will". Only in this way is given what we call an "open and infinite" multiplicity. This multiplicity is evidently the same, either we progress engendering it in time, or attracting what arbitrarily matches it, and so enlarging the series of real intuitions, either we had interrupted it earlier. (Husserl, 1999: 413)

But to be able to proceed in this way we easily see that the appearances must have undergone a change in their ontological status: they are no longer appearances of real phenomena, but of possible phenomena belonging to a

\footnotetext{
${ }^{5}$ Later (Husserl, 1968: 68) Husserl will say that every kind of experience has its particular style and all these styles are connected in a more general style that determines the way the world can be experienced by us.
} 
possible world. That's why I can speak, as I did before, of the Eiffel tower. It is no more the real mundane Eiffel tower that I can see in a real city, Paris, the capital of a real country, France. It's the Eiffel tower as a possible object, i.e. an object that has the same categorical form of any other object existing in any real or possible world (Bachelard, 1957: 229).

Before moving forward let's look to another possible case: an appearance may belong to two different series. If I intend a brown hat, I can intend it as an instantiation of the eidos brown or of the eidos hat. Two different intentions have two different kinds of fulfilment. That's why pointing to an object can be so ambiguous: while pointing to a brown hat I may be pointing to two different things (as if I were answering two different questions: "what is a hat?" or "what is the color brown?"), or I may be engaged in the process of subjecting two different - and arbitrarily chosen - appearances to different processes of variation, in order to grasp different essences ${ }^{6}$. In either case we have the same sense-content, although interpreted in different ways. But, as essences can relate to each other as genus and species, it is also possible that two different appearances, belonging to two (or more) different series, may also belong to the same series when this last series pertains to a higher level, i.e. embraces the former as a common genus. A certain green with its particular brightness may be an instantiation of the eidos «green», or, along with e.g. a certain red, may be, regardless its brightness, an instantiation of the eidos "color". The same happens with numbers: 2 and 3 may belong to two different series (even numbers and odd numbers) or to the same series (the integers).

\section{Perception of individuals and consciousness of universals}

What's the real nature of the issues addressed by Husserl in those initials paragraphs of Ideas I and in the Second Logical Investigation? I think Husserl is trying to explain the conditions in which we pick up an individual phenomenon. The paradox here is that we never really pick it up as an individual tout court, but always as an individual of such or such a species and

\footnotetext{
${ }^{6}$ Intending something specific (a universal), intending something individual or even a part of an individual has some phenomenological communities. $C f$. Husserl (1984b: 113-114).
} 
integrated in a set of formal relations with other individuals. This process is not equivalent to saying that an appearance is related to some hidden characteristics that must be supposed to exist but never appear in any possible experience; it only means that actual and possible appearances are so closely connected as to constitute the meaning of what appears.

When we think in the appearance of an individual phenomenon we don't pay attention to some paradoxes because (except in situations in which they have undergone some changes) a second or a third perception of the same phenomenon seems to be identical with former perceptions (Husserl, 2012: 2223). But, from the moment we take into account the time that elapsed between the first and the second appearance, we are forced to note a relation between individuals and universals. A consciousness of the universal is necessary to acknowledge that e.g. the same moment «red color» appears twice. Usually, we have some difficulty in acknowledging this fact. Natural consciousness, as William James remarked, has a marked preference for substantive states - a bird, this table before me, this brown hat, a blue sky - and not for relational or transitive states: for instance, this bird as an instantiation of a species, or the relation between a certain "a" and a certain " $b$ " as an example of a formal relation that would subsist for any "a's" and "b's", or even the identity of a human being in two different moments of its existence. Natural language also won't help us much here (James, 1909: 210).

Transitive states have something to do with what James also called the fringes of an object, although they don't completely coincide. Transitive states are states of consciousness in which what is given appears in a certain relation to another thing (James, 1909: 204). It corresponds broadly with what Husserl used to call the external horizon of an object. (Of course the external horizon may be composed of objects quite different from the one I am focused at a certain moment.) A fringe, according to James, is a particular kind of transitive state. There is a fringe when certain images come to the mind that seem to have a close relation to the object being perceived. Can we keep these images as valid for our knowledge of the object perceived? Yes, according to James, if those images "run" in agreement with our expectations, i.e. if they allow us to improve the expected knowledge (James, 1909: 216). The phenomenon of the fringe is, in the first place, at the origin of a typical world-image, consisting in a more or less coherent and structured system of references; in the second place, 
from the stand-point of phenomenology, it is a condition of the process of variation, although the last is not reducible to the fringes.

This problem is also at the core of the Third and Fourth Lessons of the Vorlesung of 1907 entitled The Idea of Phenomenology. But here Husserl addresses it from a somewhat different angle. In the stream of consciousness - says he at the beginning of the Fourth Lesson - individual objects come and go, we never experience the same objects, or we never experience the same object twice as exactly the same. Of course, it belongs to the essence of any lived experience of a cognitive kind to be directed towards an object, or to intend it, while it does not belong to the essence of an object to be intended by a consciousness (Husserl, 1950b: 55), although it must have the possibility of being related to an actual consciousness. But the important thing lies elsewhere. I can suspend my belief in the existence of every transcendent object and keep only the evidence of my cogitatio. But if I look to its immanent content I will find something more than an immanent content referring to a singular individual object, with its independent or dependent parts. If a singular individual object is really given, isn't there something more that I must reckon as intuitively given in order to be able to apprehend that singular individual? Husserl says that external perception is unable to achieve what it always wants to achieve (Husserl, 1966: 3). Why?

Let's suppose I say “this is a raincoat". An intended raincoat - and we don't need to bother with its possible existence in the real world - has no syntactical form. It's what Husserl labels a "Dies da", something that is here (Husserl, 1950c: 34). Still, I need the logical form and its counterpart in the linguistic expression (Husserl, 1950b: 51) in order to be able, not only to communicate my perception of a raincoat, but also to have an actual perception of it with its characteristic qualities. Perhaps the Husserlian notion of "expression of a perception", in the $6^{\text {th }}$ Logical Investigation, can also be of some help here. The core of Husserl's argument is that when we assert something the meaning of the assertion is not the mere consequence of an association between a perception and a verbal sound (Husserl, 1984b: 551). The raincoat I am looking at has a color, for instance, it is blue. When I see a subject " $S$ " with a predicate "p" (for instance, its dependent moment "blue color") I must see "p" as I see "S", although it's not the same kind of vision. And as long as I see an "S" that is "p" and say " $\mathrm{S}$ is p", the "is" that connects both has also to be picked up in 
some kind of vision (Husserl, 1984c: 318-319). But let's look more closely to what is happening here:

\section{$S=$ a raincoat}

$\mathrm{S}$ is $\mathrm{p}=$ this raincoat is blue

" $\mathrm{S}$ " is what Husserl calls a nucleus of the syntactical formation "S is p"; I can't analyze it. Of course "S" could perhaps be not a raincoat but a hat, but then it would be another nucleus, as impossible to analyze as the first one. A hat is a hat, like a raincoat is a raincoat, regardless its color. But here is the problem: a raincoat is a raincoat like any other raincoat; this one I am perceiving is just the one of a kind. That's why Husserl calls raincoats (or hats) "materially filled ultimate essences" (Husserl, 1950c: 34) ${ }^{7}$. They are ultimate essences because "under" them we only find the instantiations of these essences I called above singular individuals, like the one I am seeing now. But when these particular instantiations are experienced as such, we also see the ultimate essence they instantiate or at least the essence of the region they belong; for instance, the essence "material thing existing in space". And so we come to our point of departure: we are always going beyond the immanent content of mere cogitationes, in order to see what we really see.

\section{Going beyond immediate experience (I)}

After intending a raincoat (that happens to be blue) I could also have said: "this is an old raincoat", or "this is my raincoat". So, at the basis of the meaning of my first assertion - "this is a blue raincoat" -, rendering it possible, something more than mere perception had to be present. I can even speak of my blue raincoat, saying, for example, it is an old raincoat torn in the shoulders, without looking at it and someone who has never perceived it may understand what I say. For my listener, the assertion is meaningful; sometimes, to understand its full meaning, he can get some help from his imagination - in my example, provided that he knows at least what a raincoat is, he can imagine it being torn in the shoulders - but in other circumstances even the imagination may be inadequate. What I am saying is: if, for Husserl, the content of a meaning is not

\footnotetext{
${ }^{7}$ The German expression is: «Sachhaltiges letztes Wesen»; I followed the English translation of Fred Kerstens, in: Husserl (1982: 28).
} 
just what appears in a perception, something more has to appear in order to give the expression of a perception its meaning.

What Husserl says is quite clear although it has been the occasion for some misinterpretations. We see an essence, or a set of formal relations, as we see an individual object, and the vision of the former is no less a vision than the vision of the latter. Knowing the essence I can understand the meaning of an assertion in those cases in which no actual perception can help me. But the vision of an essence is also no more than that, although it happens in a different kind of intentional acts. «Essences», in this sense, are not just predicates, as was the case with Aristotle's «second substances» (genus and species); Husserl stresses they are objects in the broad sense of logical subjects of possible true predications (Husserl, 1950c: 15). They have their specific modes of givenness prior to all predicative thinking, and their specific personal identity.

A footnote to $\S 3$ of Ideas I (Husserl, 1950c: 15), is particularly important for us here, although today we are able to read it with full knowledge of the development of Husserl's thought, and of all his personal work that remained unpublished until after his death. It was not the case with Husserl's contemporaries. Husserl is criticizing the use of the term «ideation», in the Logical Investigations, to characterize the intuitive acts aiming to apprehend essences. And he says that we need a more appropriate term able to embrace not only adequate intuitions but also the obscure and non-intuiting consciousness. As, while speaking about this last kind of consciousness, Husserl is not speaking about the consciousness of individual objects, we must conclude that there are other and so to speak more imperfect forms of universals - at least in comparison with essences - but no less necessary to the experience of individuals. As far as we go back from conscious intentional experiences with explicit cognitive aims to more elementary forms of experience, we find as a permanent feature the necessity to go beyond what is empirically given. We can speak of a permanent split or gap between the "Dies da" and the universal of which he is a singularization ${ }^{8}$. But the most interesting is the fact that this gap characterizes all levels of experience, even those in which the universal is not yet an essence.

\footnotetext{
${ }^{8}$ This gap (Spannung) is the focus of the book of (Eley, 1962).
} 


\section{Phenomenological reduction}

It has been much debated if the previous analysis were conducted before phenomenological reduction, or if the reduction was in a certain way presupposed by them. I think that the reduction was already presupposed but, at the same time, they were intended by Husserl as a kind of introduction to it, perhaps as a way of making it more acceptable by those who lived in the natural attitude. This kind of procedure will be used later by Husserl in Formal and Transcendental Logic, where the phenomenological reduction is explicitly mentioned only in $\S 102$, and declared as having been conducted earlier (Husserl, 1974: 275). The addressees of the book of 1929 were in the first place logicians and mathematicians, and Husserl wanted to show them that the kind of operations they usually carried on - that we can broadly label «idealizations» and «formalizations» - suppose the practice of a phenomenological reduction to which they were not focused and whose meaning they ignored. In the context of the specific set of problems this book intended to address, Husserl's aim was to show that the obvious natural or mundane use of formal logic received its meaning from logic considered as a science of all possible worlds, and this in turn supposes that we have discovered the subjectivity that precedes the meaning of any real or possible world.

It's debatable if we can find in William James something similar to a phenomenological reduction ${ }^{9}$. Regarding the laws of association of psychical phenomena, James says, in Chapter XVI of his Textbook of Psychology that they are, in the first place, laws that regulate some brain states. In the same way, he had spoken, in the famous Chapter XI of his book, on the stream of consciousness, about brain states of feeble intensity in order to explain the existence of relations between the "theme" of a present state of consciousness and the halo that surrounds it (James, 1909: 214-215). But brain states are not enough for James, because those laws of association can explain either pleasant or unpleasant associations, and so the specific psychical content of those states gets no explanation (James, 1909: 333-334). And, analyzing the stream of consciousness, he makes another important remark: when in two different moments of our stream of consciousness we say that the same object appears,

${ }^{9}$ Husserl, of course, denies it. Cf. Husserl (1954: 267). 
in spite of the fact that the sensations received are very different - for instance, a leaf may look dark green in poor lightning conditions, and bright green at the open air in a shiny day -, it's because the object appearing and the appearance of the object have to be distinguished. Wittgenstein also addressed a similar problem in his writings about the philosophy of psychology. He asks why different behaviors can result from the same stimuli, for instance, the head of a lion seen in the savanna and seen in a zoo (Wittgenstein, 2014: 163). He correctly notes that we always perceive something as such and such, and that's what explains the differences in the way we react.

The same analysis of the stream of consciousness makes James establish another important phenomenological distinction. James says that there is no immediate correspondence between the parts of an object and the lived experience of that object. As is well known, the empiricist point of view that goes back to John Locke, defends exactly the opposite. Gestalt psychology was to prove that James was right and empiricism was wrong. According to Gestalt psychology, no causal relation between stimuli coming from parts of an object and the sensory organs that pick them up can explain the unity of the object perceived (Guillaume, 1937: 51) ${ }^{10}$. Husserl stressed the fact that the consciousness of unity is a homogeneous act, an almost spontaneous process of fusion, or, in other words, a synthesis without an explicit consciousness of identity (Husserl, 1984c: 279). Only by analysis is it possible to uncover its elementary components. Now, if this is the way modern sensualism is to be overcome as a result of intentional analysis, perhaps Husserl was not entirely fair in his critics of James' theory of perception.

That's enough regarding methodological procedures. Much more important is what can be done after phenomenological reduction, or, to put it the other way round, what can't be done if we don't make it. I think the whole phenomenological theory of perception would become unintelligible, as well as the criticisms Husserl addresses to Brentano (Mohanty, 2005: 5). If for Husserl not all mental states are intentional it's because phenomenological

\footnotetext{
${ }^{10}$ Of course, when we say that for phenomenology an object perceived is always a pole of identity, we are not denying that it is the same object to which sensory experience may be causally related, either from the point of view of psychology or from the point of view of physiology.
} 
reduction has allowed to distinguish the meaning-giving acts - the only that are properly intentional - from other states of mind lacking intentionality. And it is also the phenomenological reduction that gives us the correct account of the fact that intentionality may be independent of the existence of the object intended and that an optical illusion is also an intentional experience.

\section{Going beyond immediate experience (II)}

How do we come to grasp essences? Or, in other words, why do we go beyond immediate experience of singular given individuals? Putting it still in another way: how do phenomena appear in lived experience in order that a perceiving consciousness comes to see something that is not empirically given? We face here a new paradox: an individual is that special kind of being that is in no need of a complement that goes beyond itself (Husserl, 2012: 25). On the other hand, it's a basic phenomenological tenet that every perception points to further perceptions, either of the same object, uncovering new aspects that were hidden in former experiences, or of other objects surrounding the first one. This process may go on indefinitely, either in space or in time (Husserl, 1973: 5). Universals and essences are cognitive devices that enable us to stop this process, building a fairly coherent world image, in which objects are of such and such a kind and relations between them are also of such and such a kind. (The process doesn't stop in the same way in natural experience and in scientific experience; and even in natural experience it is far more complex than is usually thought ${ }^{11}$. I won't address this issue for the moment.)

Husserl and James have a remarkably similar way of thinking the relation between the experience of a singular object and what stands beyond that experience ${ }^{12}$.That's what the analysis of Husserl's concept of "expectation" and James' concept of "fringe" will show us. Husserl stresses the fact that every past experience prescribes the future experience a «style of similarity»; this means that any actual experience of an object follows the same lines of

\footnotetext{
${ }^{11}$ But - says Husserl (Husserl, 1966: 6) - even if natural experience has no immediate objective meaning from the point of view of scientific knowledge, science is only a theoretically determined mode of thinking that deviates from natural experience.

${ }^{12}$ Compare Husserl (1968: 70) and James (1909: 211).
} 
interpretation as the past ones and passes them on to the future. There arises an expectation that the train of sense ${ }^{13}$ of former experiences will keep its validity. Of course, if we don't make phenomenological reduction the temptation is great to establish some kind of causal connection between present experiences and the cultural processes (namely, education) that have conditioned our way to look at phenomena. No one can't deny that this connection exists. But the way we learned to perceive would be ineffective if it was not a characteristic of intentional consciousness to be always attentive to the horizon surrounding the intended object.

Another more complex situation arrives when we say that we are perceiving someone's joy or pain (Husserl, 1973: 10). In fact we don't actually perceive it, but only some bodily (namely, facial) expressions in which we "see" the appearance of those states of mind or emotions. Perhaps we say someone is in pain because his facial expressions are similar to mine, when I feel pain, or similar to those people who, when they have similar facial expressions, utter the words: «I feel pain». That's not very important. The important fact is that I must have some knowledge of a universal state called "feeling pain" in order to be able to recognize the present instantiation of a painful state.

Does every perception of an individual object necessarily become the experience of an instantiation of a universal? If so, why does this happen? Of course the easier way of answering these questions is to say: every particular points to a universal of which it is the particular and could not avoid doing so since it is the particular of that universal. It's not a very good answer. Instead we have to look at the experience of a particular as if we didn't know anything about universals. That's what phenomenological reduction once again allows us to do as Husserl tries to demonstrate in $\S \S 3$ and 4 of Ding und Raum ${ }^{14}$. But William James offers us an easy way to address the issue (James, 1909: 217). When we hear someone speaking we don't pick up words in isolation. Even a unique word may be understood as an abbreviation of a longer sentence, or may leave the hearer in the expectation of the next words that will give the sentence its full meaning. And when this happens, the

\footnotetext{
${ }^{13}$ I follow John Scanlon's translation of Sinneszug, in Husserl (1977: 52).

${ }^{14}$ There are some small problems in the analysis of these $\S \S$, and the editor of Hua XVI calls our attention to them in footnote 1 to p. 13. I will disregard those problems now since I think they are unimportant to my topic. Anyway, see also Husserl (1968: 71).
} 
hearer is not expecting to hear just any word: the word or words heard point beyond themselves to certain other words not yet heard. If, for instance, we were listening to a sentence in French, we don't expect to hear English words. This can be easily proved by pointing to a well-known fact: if we hear a French sentence without paying much attention to it, the contrast ensuing the unexpected hearing of an English word can suddenly arouse our attention.

Phenomenological reduction makes all this much clear. Having disconnected the "position" of particular existent objects, I am able to describe the modes of their appearances just as they appear; if something in their appearance points beyond that appearance I must be able to apprehend it and to describe the way I apprehended it. There is no other legitimate way of proceeding. And if someone argued that a real perception of a real object in our real world always involves the reference to an horizon of other real objects of which it is causally dependent and to a subject that perceives them, we would answer the following: 1) I can only presuppose that the horizon determines causally the object I am perceiving if that causal relation is a part of my lived experience of the object; 2) the real (human) act of perceiving determines the way of appearance of the object perceived if that determination is also perceived and not just presupposed as the result of some kind of knowledge (for instance, of the characteristics of the human eye) I got independently of my experience (Husserl, 1973: 11). This is what Husserl calls the intentional implications of an act. And I would say that James has helped us to understand the nature of these implications.

\section{Bibliography}

BACHELARD, S. (1957). La Logique de Husserl. Paris: PUF.

EleY, L. (1962). Die Krise der Apriori in der transzendentalen Phänomenologie Edmund Husserls. Den Haag: Martinus Nijhoff.

Guillaume, P. (1937). La Psychologie de la Forme. Paris : Flammarion.

Gurwitch, A. (1957). Théorie du Champ de la Conscience (trad. Michel Butor). Paris: Desclée de Brouwer.

HuSSERL, E. (1950a). Cartesianische Meditationen (Husserliana I). Den Haag: Martinus Nijhoff. 
- (1950b). Die Idee der Phänomenologie (Husserliana II). Den Haag: Martinus Nijhoff.

- (1950c). Ideen zu einer reinen Phänomenologie und phänomenologischen Philosophie (Husserliana III). Den Haag: Martinus Nijhoff.

- (1954). Die Krisis der europäischen Wissenschaften und die transzendentale Phänomenologie (Husserliana VI). Den Haag: Martinus Nijhoff.

- (1966). Analysen zur passiven Synthesis (Husserliana XI). Den Haag: Martinus Nijhoff.

- (1968). Phänomenologische Psychologie (Husserliana IX). Den Haag: Martinus Nijhoff.

- (1973). Ding und Raum (Husserliana XVI). Den Haag: Martinus Nijhoff.

- (1974). Formale und transzendentale Logik (Husserliana XVII). Den Haag: Martinus Nijhoff.

- (1977). Phenomenological Psychology (trans. John Scanlon), The Hague: Martinus Nijhoff.

- (1982). Ideas pertaining to a Pure Phenomenology and Phenomenological Philosophy (trad. Fred Kersten). The Hague: Martinus Nijhoff.

- (1984a), Logische Untersuchungen, Zweiter Band, Erster Teil (Husserliana XIX/1). Den Haag: Martinus Nijhoff.

- (1984b), Logische Untersuchungen, Zweiter Band, Zweiter Teil (Husserliana XIX/2). Den Haag: Martinus Nijhoff.

- (1984c). Einleitung in die Logik und Erkenntnistheorie (Husserliana XXIV). Den Haag: Martinus Nijhoff.

- (1999). Erfahrung und Urteil. Hamburg: Felix Meiner.

- (2012). Zur Lehre vom Wesen und zur Methode der eidetischen Variation (Husserliana XLI). Dordrecht / Heidelberg / New York / London: Springer. JAMES, W. (1909). Textbook of Psychology; French trans.: Précis de Psychologie. Paris: Marcel Rivière.

MCINTYRE, R. and SMITH, D. W. (1989), «Theory of Intentionality». In: J. H. Mohanty and William R. McKenna (ed.). Husserl's Phenomenology: a Textbook. Washington (DC): Center for Advanced Research in Phenomenology and University Press of America, 147-179.

MOHANTY, J. H. (2005). «Husserl's concept of intentionality». In: Rudolf Bernet / Donn Welton / Gina Zavolta (ed.). Edmund Husserl, Critical 
Assessments of Leading Philosophers, Vol. III. London and New York: Routledge, 3-30.

Wittgenstein, L. (2014). Últimos escritos sobre a Filosofia da Psicologia (trad. de António Marques, Nuno Venturinha e João Tiago Proença). Lisboa: Fundação Calouste Gulbenkian.

Carlos Morujão is Full Professor at the Faculty of Human Sciences of the Universidade Católica Portuguesa. He is also, since June 2013, Director of the Center for Philosophy Studies of the same Faculty. Between 2007 and 2011 he coordinated the research project "The Reception of the French Revolution in German Philosophy", funded by the Portuguese Foundation for Science and Technology. He has taught the curricular units of History of Contemporary Philosophy, History of Modern Philosophy and Philosophy of Knowledge. His main interests in research are currently focused on the Phenomenology of Edmund Husserl, of whom he translated the Logical Investigations into Portuguese (in collaboration with Pedro M. S. Alves). He has published essays in Portugal, Spain, France, Germany, the United States and Brazil. He is a member of the Iberian Network of Fichtean Studies and a founding member of the Portuguese Association of Phenomenological Philosophy. His last book is entitled Caminhos da Fenomenologia, and was published in 2015 by the Catholic University Publishing House. 